\title{
High-Yield Production of Fuel- and Oleochemical- Precursors from Triacylglycerols in a Novel Continuous-Flow Pyrolysis Reactor
}

\author{
Yaser Shirazi, Sridhar Viamajala* and Sasidhar Varanasi \\ Department of Chemical and Environmental Engineering, University of Toledo, \\ Toledo $\mathrm{OH} 43606$
}

* Corresponding author

Email: sridhar.viamajala@utoledo.edu

Phone: 419-530-8094

Fax: 419-530-8086 


\begin{abstract}
In this study, conversion of soybean oil was carried out in a continuous pyrolysis system with feed injected through an atomizer. This allowed introduction of micron-sized droplets of oil that could be rapidly vaporized inside the reactor. With this novel design, we were able to achieve feed vapor residence times $(\tau)$ of 6-300s without use of carrier gas, which would significantly reduce the overall cost of pyrolysis. Effects of reaction temperature $\left(450<\mathrm{T}_{\mathrm{rxn}}<500\right.$ ${ }^{\circ} \mathrm{C}$ ) and $\tau$ on conversion, product yields and composition were investigated. At the optimum experimental conditions of $\mathrm{T}_{\mathrm{rxn}}=500{ }^{\circ} \mathrm{C}$ and $\tau=60 \mathrm{~s}$, the yield of pyrolysis liquids was as high as $88 \%$ (relative to feed mass). Under these conditions, the identified products consisted of $38 \%$ hydrocarbons $\left(22 \% \mathrm{C}_{5}-\mathrm{C}_{12}\right.$ and $\left.16 \%>\mathrm{C}_{12}\right), 33 \%$ long-chain fatty acids $\left(\mathrm{C}_{16}-\mathrm{C}_{18}\right.$, but primarily oleic acid) and $15 \%$ short-chain fatty acids $\left(\mathrm{C}_{6}-\mathrm{C}_{12}\right)$. Upon distillation of the liquid products, the long-chain fatty acids were cleanly separated from the hydrocarbons. Overall, our results demonstrate the feasibility of producing liquid products at high yields, including a wide range of fuels (gasoline, jet and diesel) and enriched oleic acid (for oleochemicals production), using our reactor design for pyrolytic conversion of vegetable oil.
\end{abstract}

Keywords: Biofuel, pyrolysis, vegetable oil, soybean oil, atomization 


\section{Introduction}

Energy-dense triacylglycerols (commonly known as triglycerides) from oil seeds or microalgae have the potential to, at least partially, displace petroleum-derived fuels [1-6]. However, triglycerides cannot be used directly in current combustion engines due to their low volatility and high viscosity [2, 7-11]. Vegetable oils, the primary source of triglycerides that are currently used for biofuel production, are typically converted to usable fuels through transesterification $[12,13]$. In this process, triglycerides react with methanol, usually in presence of a homogenous catalyst (e.g. sodium hydroxide or methoxide), to produce a mixture of fatty acid methyl esters (FAMEs; commonly known as biodiesel) [14, 15]. Since the transesterification reaction is reversible, excess alcohol is required to shift the reaction towards ester production; thus, unreacted alcohol along with catalyst and glycerol need to be separated /recovered at the end of reaction. Also, the presence of free fatty acids in the feedstock leads to saponification, which results in the loss of catalyst and a decrease in the yield of esters [16]. Finally, while biodiesel is compatible with petro diesel, it exhibits a relatively high melting point (which limits its usage in cold climate regions) and lower oxidative stability compared to diesel $[4,8,17,18]$. As a result, use of biodiesel as a fuel is somewhat restricted since it is not considered as a "drop-in" alternative to hydrocarbon fuels and does not meet the ASTM D975 specification in the United States and EN 590 in Europe.

As an alternative, pyrolysis (or thermal cracking in the absence of $\mathrm{O}_{2}$ ) of vegetable oil can produce hydrocarbons that are compatible with a variety of petro-fuels such as gasoline, jet and diesel [19-22]. Studies on pyrolysis of seed oils, such as canola, palm, and soybean reveal that the primary compounds in the product are paraffins, olefins, carboxylic acids, and small 
amounts of aromatics [23-27]. Although a mixture is produced, the pyrolysis products can be separated (e.g. using distillation) and used either directly or processed by common refinery methods such as hydrogenation, hydrotreatment or alkylation to obtain gasoline and/or diesel like fuels. Further, unlike transesterification, conversion of triglycerides by pyrolysis avoids the use of methanol and unrecoverable homogenous catalysts. In addition, the un-degraded longchain fatty acids from pyrolysis (e.g. oleic acid) can be separated from hydrocarbons to serve as feedstock for oleochemical production [28, 29].

Pyrolysis of vegetable oils has typically been carried out in batch reactors at a temperature range of $300-500{ }^{\circ} \mathrm{C}$ and atmospheric pressure $[9,30]$. However, batch processes are not appropriate for commodity scale industrial operations due to low throughput. In addition, most batch studies report low yield of liquid products, likely due to the high residence time in these closed systems which allows secondary reactions of primary products to low molecular weight $\left(\mathrm{C}_{1}-\mathrm{C}_{4}\right)$ noncondensable gases. For example, Chang and Wan [31] performed batch pyrolysis of tung oil at $450{ }^{\circ} \mathrm{C}$ and residence time of $100 \mathrm{~min}$ and reported only $55 \%$ yield of liquid products. More recently, Kubatova et al. [32] conducted batch pyrolysis of canola and soybean oil at $440{ }^{\circ} \mathrm{C}$ but at a lower residence time of $10 \mathrm{~min}$ and also with high hydrogen pressure $(2200 \mathrm{kPa})$. This approach resulted in higher organic liquid product (OLP) yields (67\% OLP for soybean oil and 61-69\% for canola oil) likely due to the shorter reaction time and in situ hydrogenation of unsaturated primary products that lowered the production of secondary noncondensable gases.

In an effort to develop a continuous process for vegetable oil pyrolysis, Idem et al. [27] performed thermal cracking of canola oil. Their reactor consisted of a fixed-bed of inert materials (ceramic and quartz glass chips) that was kept at $500{ }^{\circ} \mathrm{C}$. Due to the high reactor 
temperature and surface area created by inert particles, feed likely vaporized and cracked simultaneously. However, the residence time was still high (18 min) and only $15 \%$ of feed was recovered as OLP in their experiments. Nearly $75 \%$ of feed was lost as uncondensed gases such as small chain hydrocarbons $\left(\mathrm{C}_{1}-\mathrm{C}_{4}\right)$ and $\mathrm{H}_{2}$.

Akin to the concepts of fast pyrolysis of solid substrates (e.g. biomass and coal), which are carried out at high temperature and short residence time to maximize liquid products [33-35], OLP yields from vegetable oils are expected to be better in continuous reactors with low residence time, since secondary reactions would be minimized due to continuous product removal and condensation. Theoretical reaction mechanisms proposed by Maher et al. [9] also suggest that liquid formation would be more favorable at low residence time. In recent times, Meier and co-workers have explored this approach in a series of studies and have reported improved liquid product yields [36-38]. For instance, continuous pyrolysis of waste fish oil during these studies resulted in the relatively high yield of $72 \%$ liquid products at reaction temperature of $525^{\circ} \mathrm{C}$ and low vapor residence time of 24s [36, 37]. In addition to short residence time, a high free fatty acid content in the feed also possibly contributed to the high yields of OLP since fatty acids are more amendable to thermal cracking than triglycerides [23]. While yields were improved, nearly $30 \%$ of feed material was still lost to uncondensed gases. An additional drawback of the reaction system proposed by Meier and co-workers is the requirement of preheating the feed. Since the objective was to quickly vaporize the feed in the reactor (for short residence time), the feed was preheated to $475^{\circ} \mathrm{C}$. Thus, while the pyrolysis residence time was short, the overall time period for which feed was exposed to high temperature was still large and could have possibly resulted in some oil degradation during preheating. Including a preheater would also increase the capital cost of the reaction system. 
From these studies reported in the literature, it can be noted that liquid product yields were typically in the range of $20-70 \%$ depending on reaction conditions, feedstock and reactor design. Liquid products, rather than gas are more desirable, since they have higher heating values on a volumetric basis and are easy to store and transport. Although pyrolysis of vegetable oil is more desirable than transesterification since it allows the direct production of hydrocarbons fuels, pyrolysis technology has not yet attracted commercial interest due to the key bottleneck of the inability to achieve high liquid yields. The goal of this study was to improve the yield of liquid products during pyrolysis. As such, conversion of soybean oil was carried out in a novel continuous pyrolysis system equipped with an atomizer. This allowed introduction of micronsized droplets of oil that could be rapidly vaporized inside the pyrolysis tube. With this design, we were able to achieve low vapor residence times without preheating the feed. Since atomization is frequently utilized in car engines, painting/coating industries, and pharmaceutical manufacturing processes, it is expected that this common approach could be easily implemented on industrial scale. The influence of temperature and vapor residence time on conversion, product yields and composition of soybean oil pyrolysis was investigated.

\section{Experimental}

\section{$2.1 \quad$ Materials}

Soybean oil was obtained from Zoyeoil (Zeeland, MI, USA). Hexane, chloroform, methanol, N-methyl-2-pyrolidone (NMP), sulfuric acid and enriched oleic acid were purchased from Fisher Scientific (Pittsburgh, PA, USA). Analytical standards for fatty acids (stearic acid, oleic acid, linoleic acid, and palmitic acid), glycerides (triolein, diolein, and monolein), FAMEs (mixtures of $\mathrm{C}_{8}-\mathrm{C}_{22}$ FAMEs), alkanes $\left(\mathrm{C}_{5}, \mathrm{C}_{6}, \mathrm{C}_{7}, \mathrm{C}_{8}\right.$ and mixtures of $\mathrm{C}_{7}-\mathrm{C}_{30}$ ), olefins-(Alphagaz 
PIANO), and aromatics-(Alphagaz PIANO) were purchased from Sigma-Aldrich (St. Louis, MO, USA).

\subsection{Experimental set-up}

All experiments were performed in a continuous pyrolysis system that is schematically shown in Figure 1. A stainless steel tube with an inner diameter (ID) of $2.18 \mathrm{~cm}$ and length of 23 $\mathrm{cm}$ served as the pyrolysis reactor. The tube was placed in a clam-shell furnace (Applied Test Systems, Butler, PA, USA) with $10 \mathrm{~cm}$ ID and $38 \mathrm{~cm}$ length and equipped with a temperature controller to maintain the set-point temperature. A high temperature ultrasonic atomizer (Sonazop, Farmingdale, NY, USA; model: HTNS40) was attached to one end of the reactor tube to introduce soybean oil into the pyrolysis reactor. The atomizer consists of an ultrasonic probe with a $4 \mathrm{~mm}$ diameter, which was operated at constant frequency of $40 \mathrm{kHz}$.

For precise control of feed flowrate, an HPLC pump (Waters, Milford, MA, USA; model: 515) was used. After pyrolysis, product vapors were passed through a condenser system which consisted of one cold-trap and two Allihn condensers connected in series. Commercial antifreeze was used as coolant for the Allihn condensers. The antifreeze was cooled to approximately -20 ${ }^{\circ} \mathrm{C}$ using dry ice and pumped through the Allihn condensers via a Masterflex ${ }^{\mathrm{TM}} \mathrm{L} / \mathrm{S}$ peristaltic pump (Cole-Parmer, Vernon Hills, IL, USA).

Prior to each experiment, the reactor was placed in the furnace and heated while being purged with pure $\mathrm{N}_{2}$ to remove any traces of $\mathrm{O}_{2}$ from the system. After the reactor reached set point temperature, the $\mathrm{N}_{2}$ purge was stopped, atomizer was turned on, feed pump was started at a set flow rate to provide a pre-specified vapor residence time (1-300 s) in the reactor. The system was operated in continuous mode for a duration of 10-170 min, depending upon the set feed flow rate. Over this period, approximately $10 \mathrm{~g}$ of soy oil was processed. The exact feed mass 
introduced into the reactor was calculated from the difference in the weight of feed tank before and after each experiment.

At the end of the experiment, the reactor furnace was turned off and allowed to cool to room temperature. Thereafter, the liquids from all condensers were collected and weighed on an analytical balance (Mettler Toledo, USA) with $\pm 0.1 \mathrm{mg}$ accuracy.

Conversion of soybean oil to non-glyceride products was calculated as

Conversion $(\%)=\frac{\mathrm{W}_{\mathrm{O}}-\left(\mathrm{W}_{\mathrm{TG}}\right)_{\text {out }}}{\mathrm{W}_{\mathrm{O}}} \times 100$

Where, $\mathrm{w}_{\mathrm{O}}$ is the mass of oil introduced into the reactor and $\left(\mathrm{W}_{\mathrm{TG}}\right)_{\mathrm{out}}$ is the mass of glycerides in collected liquid.

The yield of pyrolysis liquids was calculated as

Yield $(\%)=\frac{\mathrm{w}_{\mathrm{L}}}{\mathrm{w}_{\mathrm{O}}} \times 100$

where, $\mathrm{w}_{\mathrm{L}}$ is the weight of pyrolysis liquids collected.

The yield of non-glyceride liquid products was calculated as

Yield of non-glyceride liquid $(\%)=\frac{\mathrm{W}_{\mathrm{L}}-\left(\mathrm{W}_{\mathrm{TG}}\right)_{\mathrm{out}}}{\mathrm{W}_{\mathrm{O}}} \times 100$

The feed was assumed to be all triglycerides.

\subsection{Fractionation of pyrolysis liquid products}

A simple lab-scale vacuum distillation unit was used to separate the components of pyrolysis liquid products. The procedure used is as follows: the liquid products collected after pyrolysis were transferred to a round-bottom boiling flask that was placed in a silicone oil bath. 
The bath was kept on a hot stir plate and heated to distillation temperature. The boiling flask was connected to a short Vigreux-type condenser followed by a Liebig condenser, and finally a collecting flask. A vacuum pump (Fisher Scientific; model: Maxima C plus) was connected to the collecting flask to maintain the distillation unit under a vacuum of $60 \mathrm{~mm} \mathrm{Hg}$. As described in section 2.2, commercial antifreeze cooled to $-25^{\circ} \mathrm{C}$ was used as a coolant for the Liebig condensers and recirculated via a Masterflex L/S pump. The collecting flask was kept immersed in liquid $\mathrm{N}_{2}$ during distillation.

\subsection{Experimental design}

According to the literature, temperature and vapor residence time are the two variables that can impact the yield and characteristics of pyrolysis products [39]. In our experiments, vapor residence times of 1, 6, 60 and $300 \mathrm{~s}$ were tested to compare flash, fast and slow pyrolysis regimes. Feed mass flowrates were adjusted to obtain the desired vapor residence time (detailed calculations are described in Section 3.1). Reaction temperatures of 450,475 , and $500{ }^{\circ} \mathrm{C}$ were selected to investigate effects of temperature. The lowest reactor temperature in our experiments $\left(450{ }^{\circ} \mathrm{C}\right)$ is above the expected volatilization temperature of triglycerides $\left(>410{ }^{\circ} \mathrm{C}\right)$ [40]. A full factorial design with twelve runs was employed. In addition, one experiment at severe operational conditions $\left(\mathrm{T}=550{ }^{\circ} \mathrm{C}\right.$ and $\left.\tau=300 \mathrm{~s}\right)$ was performed to analyze the liquid products composition and the productivity of system at harsh reaction conditions. In this paper all experiments are represented by a T- $\tau$ code system, where $\mathrm{T}$ represent the reaction temperature in ${ }^{\circ} \mathrm{C}$ and $\tau$ indicates the vapor residence time in seconds. For instance, the code 475-6 describes an experiment at reaction temperature of $475^{\circ} \mathrm{C}$ and a vapor residence time of $6 \mathrm{~s}$. 


\subsection{Feedstock analysis}

To identify and quantify fatty acid constituents in the feedstock, soybean oil was transesterified to FAMEs by reacting $5 \mathrm{mg}$ soybean oil with $2 \mathrm{~mL}$ of a methanol-sulfuric acid mixture $(95 / 5 \mathrm{vol} . \%)$. The reactants were placed in a $5 \mathrm{~mL}$ sealable vial and immersed in a hot water bath at $90{ }^{\circ} \mathrm{C}$ for $90 \mathrm{~min}$. Afterward, the reaction mixture was cooled and the FAMEs were extracted into $2 \mathrm{~mL}$ hexane (extraction conditions: $90{ }^{\circ} \mathrm{C}, 15 \mathrm{~min}$ ). The extract was analyzed by gas chromatography (as described in section 2.6).

\subsection{Gas chromatography analysis}

To identify and quantify chemical compounds in the pyrolysis products and feedstock, a gas chromatograph (Shimadzu 2012 plus) equipped with a flame ionization detector (FID) and an auto sampler (AOC-20i) was used. For analysis of triglycerides, diglycerides, long-chain fatty acids and feedstock FAMEs (obtained from feedstock transesterification, Section 2.5), an RTXbiodiesel (Restek, Bellefonte, PA, USA) column was employed (15 m length, $0.32 \mathrm{~mm} \mathrm{ID}$, and $0.1 \mu \mathrm{m}$ film thickness). The injector and FID detector temperatures were $370{ }^{\circ} \mathrm{C} ; 1 \mu \mathrm{L}$ sample was injected. $\mathrm{H}_{2}$ was used as the carrier gas with a flowrate of $6.02 \mathrm{~mL} \mathrm{~min}^{-1}$ and a split ratio of 1:10. The column temperature was initially set at $60^{\circ} \mathrm{C}$ for $1 \mathrm{~min}$, and was subsequently heated at a temperature ramp rate of $10{ }^{\circ} \mathrm{C} \min ^{-1}$ to $370{ }^{\circ} \mathrm{C}$; this final temperature was maintained for 5 min at the end of the run. FID detector response was first calibrated using appropriately diluted (in hexane or chloroform) FAME standards, long-chain fatty acid standards, monoolein, diolein and triolein $\left(0.05-5 \mathrm{mg} \mathrm{mL}^{-1}\right)$. For sample analysis, the samples were diluted to concentrations of 2-5 mg-sample $\mathrm{mL}^{-1}$ in chloroform (for pyrolysis biooil) or hexane (for FAME analysis of transesterified feed). Monoglyceride, diglyceride, triglyceride, FAME and long-chain fatty acid 
concentrations in the samples were estimated from calibration curves as previously described $[41,42]$.

For preliminary analysis of hydrocarbons in the pyrolysis products, an RTX-5 (Restek, Bellefonte, PA, USA) column (15 m length, $0.25 \mathrm{~mm} \mathrm{ID}$, and $0.25 \mu \mathrm{m}$ film thickness) was used. The injector and FID detector temperatures were kept at $350{ }^{\circ} \mathrm{C} ; 1 \mu \mathrm{L}$ sample was injected. $\mathrm{H}_{2}$ was used as the carrier gas with a constant flowrate of $1 \mathrm{~mL} \mathrm{~min}^{-1}$ and a split ratio of 1:10. The column temperature was initially at $30{ }^{\circ} \mathrm{C}$ for $3 \mathrm{~min}$, and was subsequently heated at a temperature ramp rate of $10{ }^{\circ} \mathrm{C} \min ^{-1}$ to $350{ }^{\circ} \mathrm{C}$; this final temperature was maintained for 3 min at the end of the run. Since the hydrocarbons were not well separated on this column, only relatively few peaks were observed, likely due to overlap of similar chemical compounds. In these analyses, calibration curves were developed using external analytical alkane standards and the concentration of each hydrocarbon group (e.g. C8 hydrocarbons) in the sample was estimated based on the calibration response of a representative alkane (e.g. C8 alkane). Pyrolysis liquid product samples were diluted to concentrations of 2-5 mg-sample $\mathrm{mL}^{-1}$ in chloroform for analysis.

For additional detailed analysis of hydrocarbons in the distilled fraction of the pyrolysis products (see Section 2.3), a DB-petro (Agilent, Santa Clara, CA, USA) column (50 m length, $0.25 \mathrm{~mm}$ ID, and $0.5 \mu \mathrm{m}$ film thickness) was employed. The injector and detector temperatures were kept at $300{ }^{\circ} \mathrm{C} ; 1 \mu \mathrm{L}$ sample was injected. $\mathrm{H}_{2}$ was used as the carrier gas with a constant flowrate of $1 \mathrm{~mL} \mathrm{~min}^{-1}$ and a split ratio of 1:10. The column temperature was initially maintained at $35^{\circ} \mathrm{C}$ for $15 \mathrm{~min}$. Thereafter, the temperature was increased at a ramp rate of $1{ }^{\circ} \mathrm{C} \min ^{-1}$ to 60 ${ }^{\circ} \mathrm{C}$. The column was then maintained at this temperature for $20 \mathrm{~min}$. Finally, the column temperature was increased to $300{ }^{\circ} \mathrm{C}$ at a ramp rate of $2{ }^{\circ} \mathrm{C} \mathrm{min}-1$ and held at the final 
temperature for 2 min at the end of the run. All samples were analyzed three times and the product compositions were calculated based on relative peak area. Mean values of the estimated composition are reported. Distilled fraction samples were diluted to concentrations of 2-5 mgsample $\mathrm{mL}^{-1}$ in chloroform for analysis.

GC-MS (Bruker, 450-GC equipped with 300-MS) analysis was performed to identify the chemical compounds in the pyrolysis products and also for quantification of derivatized shortchain fatty acids (see more detailed description in the next paragraph). An Agilent DB-5MS fused silica capillary column (length: $30 \mathrm{~m}$, ID: $0.25 \mathrm{~mm}$, and film thickness: $0.25 \mu \mathrm{m}$; Agilent Technologies, Santa Clara, CA) was used. The injector temperature was held constant at $300{ }^{\circ} \mathrm{C}$ and a split ratio of 1:100 was maintained during each sample analysis. $1 \mu \mathrm{L}$ sample was injected. Helium was used as carrier gas with constant column flow of $1.0 \mathrm{~mL} \mathrm{~min}^{-1}$. The column was programed as follows: constant temperature of $30{ }^{\circ} \mathrm{C}$ for $10 \mathrm{~min}$, followed by a temperature ramp $10{ }^{\circ} \mathrm{C} \mathrm{min}{ }^{-1}$ to $300{ }^{\circ} \mathrm{C}$ and a final hold for $10 \mathrm{~min}$. The transfer line, ion source, and manifold were maintained at 300,150 , and $40^{\circ} \mathrm{C}$, respectively. Chemical compounds corresponding to chromatogram peaks were identified using NIST2008 mass spectral database. A minimum 70\% confidence level was used as a threshold for positive identification of IDs provided by the spectral analysis software.

For direct analysis via GC-MS, liquid samples obtained after pyrolysis or after subsequent distillation, were diluted in chloroform (2-5 mg-sample mL-chloroform $\left.{ }^{-1}\right)$. In addition, these samples were also treated with acidified methanol to derivatize fatty acids within the sample to fatty acid methyl esters. Kubatova et al. [32] have suggested that this derivatization procedure improves the sensitivity of fatty acid detection, especially for the detection of short chain fatty acids. The derivatization procedure was similar to the transesterification method 
described in Section 2.5. In brief, $5 \mathrm{mg}$ of biooil samples were reacted with $2 \mathrm{~mL}$ of a methanolsulfuric acid mixture (95/5 vol. \%) at $90{ }^{\circ} \mathrm{C}$ for $90 \mathrm{~min}$. Afterward, the samples (now containing FAMEs) were extracted into $2 \mathrm{~mL}$ hexane and analyzed by GC-MS as described in the previous paragraph.

\section{Results and Discussion}

\subsection{Design of the experimental pyrolysis system}

To prevent secondary reactions and achieve a high yield of liquid products, we focused on designing a reactor that would allow rapid vaporization of feed. It was anticipated that such a design would provide the means to maintain a short residence time of feed due to its rapid transition to vapor phase which quickly flows out of the reactor. In addition, liquid build up would be avoided and thereby polymerization/coke formation would be prevented. One way to improve vaporization/volatilization rates of viscous vegetable oil is by injecting it into a hot reactor in the form of small droplets. This would create a very large surface area to promote rapid heat transfer and vaporization of the oil. In this study, an atomizer was used to create microscopic oil droplets. In addition to rapid vaporization, this approach allows uninterrupted addition of feed and hence continuous operation of the reactor. Stagnation of fluid was also avoided due to rapid formation of vapors. Finally, by this approach the vapors and volatile products were pushed out without the need to apply additional carrier gas. Thus, the cost associated with supplying and heating the carrier gas could be eliminated. Elimination of carrier gas would also minimize the condenser size.

Disintegration of a liquid film into fine droplets in the surrounding environment is known as atomization [43]. In the ultrasonic atomizer used in our reactor, the mechanical vibration generated from a piezoceramic element is transferred to the in-flowing liquid creating capillary 
waves, which disintegrate into fine droplets and form a dense fog that exits the atomizer nozzle [44]. The droplet size generated by atomizers can be estimated from the characteristics of the atomization device as well as fluid properties and flow rates. Based on the correlation proposed by Rajin et al. [45], we estimated that the average droplet size of oil ejected from our atomizer would be between approximately 20 to $60 \mu \mathrm{m}$ (depending on feed flowrates) under ambient temperature conditions [soybean oil density $910 \mathrm{~kg} \mathrm{~m}^{-3}$ [46], surface tension $32.9 \mathrm{mN} \mathrm{m}^{-1}$ [47], and viscosity $38 \mathrm{mPa}$-s [48]]. At high temperature pyrolysis conditions, droplet size would be lower; however, we were unable to estimate the droplet size within the hot reactor due to unavailability of temperature dependent vegetable oil properties.

Assuming that vaporization is nearly instantaneous, Equation 4 derived from the Ideal Gas Law was used to calculate the mass flowrates of the generated vapors at different reaction temperatures to obtain a target vapor residence time.

$$
\tau=\frac{\operatorname{LAPM}_{\mathrm{w}}}{\mathrm{RTm}}
$$

Where, $\mathrm{L}$ is reactor length $(\mathrm{m}), \mathrm{A}$ is reactor cross sectional area $\left(\mathrm{m}^{2}\right), \mathrm{P}$ is pressure $(\mathrm{atm})$, $\mathrm{M}_{\mathrm{w}}$ is soybean oil molecular weight $\left(875 \mathrm{~g} \mathrm{gmol}^{-1}\right), \mathrm{R}$ is universal gas constant $\left(0.000082 \mathrm{~m}^{3}\right.$.atm $\left.\mathrm{mol}^{-1} \cdot \mathrm{K}^{-1}\right), \mathrm{T}$ is reactor temperature $(\mathrm{K})$, and $\tau$ is vapor residence time (s). Mass flowrate was divided by soybean oil density to estimate the feed volumetric flowrate (see more detailed derivation of Equation 4 in Supplementary Information, Figure S1). In Equation 4, the residence time is a function of temperature and feed mass flow rates and can be adjusted by varying these parameters.

The residence time can also be calculated based on product composition. Since the average molecular weight of the product is much lower than the feed, the residence time 
calculated based on product composition will be lower since residence time is directly proportional to the molecular weight. The detailed calculations for product molecular weights and product-based residence time estimates are shown in pages 1-4 of Supplementary Information. In addition, Table S1 of supplementary information shows the correlation between feed- and product- residence times. Since product composition changes with reaction conditions, Table S1 provides an estimate of the residence time based on output product $\left(\tau_{\mathrm{o}}\right)$ under the various experimental conditions reported in this manuscript. From this table, it can be seen that residence time values are drastically different when reaction temperatures are increased for the same feed flow rate. In addition, it is important to note that the estimates of residence time based on product composition are likely less accurate than the residence time estimates from feed mass $(\tau)$ due to the uncertainty (especially under more severe reaction conditions) associated with unidentified liquid and uncondensed gas products. Finally, since the reactor is of a column design ("plug-flow" rather than a "complete back mix"), the product compositions likely vary along the length of the reactor.

Since the primary purpose of residence time calculation (for the gas phase reaction described here) is to allow empirical reactor design, rather than to assess fundamental reaction kinetics, the choice of feed-based residence time estimates allow for correlation of product yields with feed flow rates - a parameter that could be easily controlled in commercial practice. As such, we have used a feed-based residence time $(\tau)$ to discuss the results of this manuscript.

Reports from literature have revealed that thermal decomposition and volatilization of vegetable oil is slow below $420{ }^{\circ} \mathrm{C}$ [49]. In addition, thermodynamic simulations of vegetable oil cracking reactions suggest that the scission of $\mathrm{C}=\mathrm{C}$ starts at $400{ }^{\circ} \mathrm{C}[50]$. To stay sufficiently above the minimum reaction temperature threshold, the lowest temperature used in our 
experiments was $450{ }^{\circ} \mathrm{C}$. Very high temperatures are also reported to decrease the liquid products yield (due to further cracking) [38], in addition to increasing the operating costs. Consequently, the highest temperature in our studies was kept at $550{ }^{\circ} \mathrm{C}$.

\subsection{Feedstock characterization}

Soybean oil was derivatized to FAMEs to quantify the fatty acid composition of feed by GC-FID. Consistent with previous observations [32], our results show that the soybean oil used in this study was comprised of linoleic and linolenic (53.4 wt. \%), oleic (30.6 wt. \%), palmitic (9.8 wt. \%), and stearic (6.2 wt. \%) acids. As expected, the majority of fatty acids in soybean oil $(84 \%)$ were unsaturated.

\subsection{Pyrolysis yield}

Figure 2a shows the increase in pyrolytic conversion (Equation 1) of soybean oil with increasing $\tau$ and reaction temperature. Thermal cracking of vegetable oil is an endothermic reaction, and is thus favored at high temperature [27]. At high reaction temperature (475-500 $\left.{ }^{\circ} \mathrm{C}\right)$, nearly $100 \%$ conversion was observed even at low $\tau(\sim 6 \mathrm{~s})$. However, at low temperature $\left(450{ }^{\circ} \mathrm{C}\right)$ complete conversion was achieved at much higher vapor residence time (60-300 s). Interestingly, at very short vapor residence time ( $\tau=1 \mathrm{~s})$ conversion of soybean oil was nearly $40-60 \%$ at all reaction temperatures, which suggests that reaction is initially fast and possibly first-order.

To assess loss of material to non-condensable gases, Figure $2 \mathrm{~b}$ shows the mass fraction of liquid product recovered relative to feed mass (Equation 2) with change in vapor residence time at the pyrolysis temperatures of our experiments. These values include unconverted feed, which is especially significant at low vapor residence time $(\tau<6 \mathrm{~s})$ (refer to Figure 2(a)). It is interesting to note that at even very short reaction residence time ( $\tau=1 \mathrm{~s})$, nearly $7-10 \%$ of feed 
mass is lost. Previous studies have demonstrated that first step in triglyceride pyrolysis is the release of the glycerol backbone and its conversion to non-condensable gases [9]. From our results, this first step appears to be rapid and seems to occur within $1 \mathrm{~s}$ of reaction. After $1 \mathrm{~s}$, loss of products as gases remains nearly constant until $60 \mathrm{~s}$. Thereafter, at high vapor residence time ( $\tau>60 \mathrm{~s}$ ) the yield of recovered liquid decreases, likely due to further decomposition of products.

Figure $2 \mathrm{c}$ shows the effects of $\tau$ and temperature on the yield of non-glyceride liquid products (equal to mass of total liquid recovered minus the mass of glyceride in liquid product; see Equation 3). For instance, at the experimental condition of 500-6, the total mass fraction of recovered liquids is $87 \%$ (relative to feed mass, Figure $2 \mathrm{~b}$ ) but contains $3 \%$ of unreacted triglyceride (Figure 2a), therefore the yield of non-glyceride liquid product for this experiment would be $84 \%$ (Figure 2c). As observed from Figure 2(c), the yield of non-glyceride liquid product increases most significantly between $0-6 \mathrm{~s}$, but decreases at high vapor residence time $\left(\tau_{\text {va p }}>60 \mathrm{~s}\right)$. At $\tau=1 \mathrm{~s}$, although yield of liquid recovered is high (Figure $2 \mathrm{~b}$ ), conversion of feed is low (Figure 2a) and thus yield of non-glyceride liquid product is low (Figure 2c). At $\tau$ between 6-60 s, due to high yield of liquid recovered (Figure 2b) and conversion (Figure 2a), high yield (>85\%) of non-glyceride liquid product was achieved.

When the glycerol backbone is released during triglycerides pyrolysis (the first step in triglyceride decomposition), acrolein $\left(\mathrm{C}_{3} \mathrm{H}_{4} \mathrm{O} ; \mathrm{MW}=56 \mathrm{~g} \mathrm{gmol}^{-1}\right)$ is produced (one mole per mole of triglyceride) which then decomposes to non-condensable $\mathrm{C}_{2} \mathrm{H}_{4}$ and $\mathrm{CO}$ [27, 31, 51]. Given this reaction mechanism, the theoretical yield of liquid from soybean oil pyrolysis was calculated to be approximately $93 \%(\mathrm{w} / \mathrm{w})$ by discounting the estimated mass of acrolein produced from the feed mass. An average soybean oil molecular weight of $875 \mathrm{~g} \mathrm{gmol}^{-1}$ was used for these calculations. In Figure 2c, the dashed line represents this theoretical maximum liquid product 
yield. When pyrolysis was performed under the reaction conditions of $6 \mathrm{~s}<\tau<60 \mathrm{~s}$ and $475<\mathrm{T}<500{ }^{\circ} \mathrm{C}$, the yield of non-glyceride liquid products was between $83-88 \%(\mathrm{w} / \mathrm{w})$ - values that are close to our theoretical prediction for maximum liquid product yield. The high yield of liquid products under these conditions (when $\tau<60 \mathrm{~s}$ ) suggest that secondary reactions were sufficiently slow such that pyrolysis products remained as condensable liquids but did not significantly decompose to non-condensable gaseous products.

At $\tau>60 \mathrm{~s}$ and $\mathrm{T} \geq 475^{\circ} \mathrm{C}$, yield of non-glyceride liquid product decreased with temperature (except at $450^{\circ} \mathrm{C}$ ) likely due to further breakdown of non-glycerides to noncondensable gases at higher reaction temperature and residence time. Interestingly, at reaction temperature of $450^{\circ} \mathrm{C}$, yield of non-glyceride liquid product continued to increase over $\tau$ between 1-300 s suggesting that secondary reactions (which cause further cracking of liquid product and gas formation) are even slower (or absent) at low reaction temperature.

In our pyrolysis system, liquid yield from pyrolysis of lipids were significantly improved (as high as $88 \%$ ) relative to previous studies (20-70\%) [9]. The high yields are likely due to the rapid volatilization of the feed and the short vapor residence time, which decreases the chance for pyrolysis products to undergo secondary reactions. Our experiments show that in order to achieve high liquid product yield, the optimal vapor residence time should be between 6-60 s. To reach such a short vapor residence time, rapid vaporization of feed is required. In our pyrolysis system, due to atomization of vegetable oil, small droplets of oil could vaporize and reach the reactor temperature rapidly, which allowed the pyrolysis to be carried out at a short vapor residence time. 


\subsection{Products analysis}

Figure 3 shows a general schematic of the principal steps involved in thermal cracking of vegetable oil as described previously in the literature [23, 24, 27, 31], and also is evident from the present work. As discussed in the previous section, the first step in thermal cracking of triglycerides is the disintegration of the glycerol backbone. Subsequently, the long-chain fatty acids (L-FAs) can further degrade via two parallel pathways. In one case, they might decarboxylate and/or decarbonylate and produce heavy hydrocarbons (Hy-HCs) (reaction 3). Alternatively, the L-FAs can degrade at the sites of the $\mathrm{C}=\mathrm{C}$ bonds and form short-chain fatty acids (S-FAs) and light hydrocarbons (Lt-HCs) (reaction 4). The Hy-HCs produced from reaction 3 can also subsequently crack at the $\mathrm{C}=\mathrm{C}$ sites and form Lt-HCs (reaction 5). In parallel, the S-FAs from reaction 4 can release $\mathrm{CO}_{2}$ and/or $\mathrm{CO}$ due to decarboxylation and/or decarbonylation and produce Lt-HCs (reaction 6). Aromatics and cyclo-compounds can also form from the Diels-Alder reaction of dienes and alkenes [27] (reaction 7). Finally, unsaturated Lt-HCs also may break down further (due to $\mathrm{C}=\mathrm{C}$ bond) and produce $\mathrm{C}_{1}-\mathrm{C}_{4}$ uncondensable hydrocarbons (reaction 8). In Figure S2 (Supplementary Information), we have illustrated the triglyceride pyrolysis reaction pathways for the thermal cracking of trioleate and show the C-C bond cleavage, decarboxylation/decarbonylation and Diels-Alder reaction pathways for this model triglyceride. Overall, the mechanisms shown in Figures 3 and S2 suggest that due to the complexity of the cracking reactions, a diverse distribution of chemicals constituents (such as LFAs, S-FAs, Hy-HCs, Lt-HCs, G, cyclic and aromatics) can be produced during pyrolysis. The mechanisms also suggest that lighter products (secondary reactions) are progressively formed with an increase in residence time. If the residence time is excessive, it is expected that a large proportion of the feed would form gases. The mechanism further suggests that with optimization 
of reaction temperature and residence time, the formation of non-condensable gases can be minimized. It might also be possible to partially control product compositions (low MW versus high MW) through changes in reactor temperature and residence time.

Product composition from pyrolysis reactions were estimated by GC analysis of the recovered liquid. Figure 4 shows the content of L-FAs $\left(\mathrm{C}_{16}-\mathrm{C}_{18}\right.$; Figure $\left.4 \mathrm{a}\right)$, S-FAs $\left(\mathrm{C}_{6}-\mathrm{C}_{11}\right.$; Figure $4 b)$, Hy-HCs $\left(>C_{12} ;\right.$ Figure $\left.4 c\right)$, and Lt-HCs $\left(C_{5}-C_{12} ;\right.$ Figure $\left.4 d\right)$ in the recovered liquids. Identification and quantification of hydrocarbons (heavy and light), and L-FAs were relatively straightforward. Concentrations of these components were estimated from GC-FID peak areas by comparison with calibration curves of known standards. However, direct identification and quantification of S-FAs was more difficult because these compounds showed low sensitivity on both GC-FID and GC-MS. Therefore, derivatization of fatty acids to fatty acid methyl esters (FAMEs) was performed to improve sensitivity as suggested by Kubatova et al. [32]. Even after derivatization, identification and quantification of S-FA methyl esters was difficult using GCFID, because of close peak proximity with Lt-HCs. GC-MS, however allowed a positive identification of the S-FAs methyl esters. Therefore, S-FAs were quantified by GC-MS by comparison of peak areas with calibration curves of S-FA methyl ester standards.

From Figure 4, one can observe that the concentrations of L-FAs (Figure 4a) in the products first increased ( $1 \mathrm{~s}<\tau<6 \mathrm{~s})$, and then decreased $(\tau>6 \mathrm{~s})$. At $\tau<6 \mathrm{~s}$, the conversion of triglycerides is incomplete (refer to Figure 2a) and L-FAs (that formed from triglycerides degradation) likely further decompose to only a small extent due to the short residence time. In other words, the rate of formation of L-FAs is higher than the rates of their decomposition when $\tau<6$ s. For instance, at $450{ }^{\circ} \mathrm{C}$ and $\tau=1 \mathrm{~s}$, although only $\sim 28 \%$ of non-glyceride liquid products were formed, the L-FA fraction of the non-glyceride liquid products was nearly $70 \%$. However, 
after $6 \mathrm{~s}$, when nearly complete triglyceride conversion was achieved (Figure 2a), the produced L-FAs would be expected to decompose via reactions 3 and/or 4 (Figure 3), when allowed to stay in the reactor longer. Thus, the L-FAs concentrations decreased when $\tau>6 \mathrm{~s}$ (Figure 4a). Interestingly, oleic acid remained the major fatty acid component of the L-FA fraction, while linoleic acid was only $5 \%$ of the total recovered liquid (Table S2; supplementary data). In contrast, the feed contained $\sim 50 \%$ linoleic and linolenic acids (refer to Section 3.2). The enrichment of oleic acid in the pyrolysis products indicates that linoleic acid (C18:2) and linolenic acid (C18:3) break down more readily than oleic acid (C18:1).

From Figure $4 \mathrm{~b}$, it can be observed that S-FA concentrations increased consistently with vapor residence time. As discussed in Section 3.2 and in the previous paragraph, fatty acid chains in soybean oil are largely polyunsaturated (linoleic and linolenic acid) and prone to $\mathrm{C}=\mathrm{C}$ cleavage [9]. These decompositions are expected to result in formation of S-FAs and Lt-HCs (Figure 2; reaction 4). Table S3 (supplementary data) shows the composition of S-FAs in the recovered liquid. From these data, it can be observed that the majority of the produced S-FAs were saturated (such as hexanoic, heptanoic, octanoic, nonanoic, and decanoic acid). In addition, the yields of nearly all S-FAs increased at higher vapor residence time and reaction temperature most likely because the cleavage of $\mathrm{C}=\mathrm{C}$ bond is an endothermic reaction. Since fatty acid chains in the parent triglyceride are predominantly unsaturated, it is reasonable to presume that these SFAs were produced by $\mathrm{C}=\mathrm{C}$ cleavage. For instance, oleic acid contains one double bond at $\mathrm{C}_{9}$ and linoleic acid has an additional double bond at $\mathrm{C}_{12}$. Cleavage of the $\mathrm{C}-\mathrm{C}$ double bond (from L-FAs) at the $\alpha, \beta$ position relative to the $\mathrm{C}_{9}$ unsaturation would produce heptanoic acid, and similar cleavage relative to $\mathrm{C}_{12}$ would produce decenoic acid. Thereafter, hydrogenation of decenoic acid (due to hydrogen generation from glycerol decomposition) could form decanoic 
acid. Heptanoic, decanoic and decenoic acid were the major S-FAs compounds observed in our products.

As observed in Figure 4c, the concentrations of Hy-HCs in liquid products also increased at $1 \mathrm{~s}<\tau<60 \mathrm{~s}$, but decreased at higher reaction times. These $\mathrm{C}_{12}$ and higher hydrocarbons were likely produced from decarboxylation and/or decarbonylation of L-FAs along with partial cracking of the fatty acid chain. The Hy-HCs that have unsaturated C-C bonds can break down and produce Lt-HCs. Like S-FAs, the content of Lt-HCs increased with $\tau$ and $\mathrm{T}_{\mathrm{rxn}}$. Formation of Lt-HCs is thermodynamically more favored at higher $\mathrm{T}_{\mathrm{rxn}}$ due to the endothermicity of cracking $(\mathrm{C}=\mathrm{C}$ cleavage $)$ and decarboxylation reactions.

Table S4 (supplementary information) shows the mass of the identified and unidentified chemical compounds in the recovered liquid as a fraction of feed mass. Production of noncondensable gases (such as $\mathrm{C}_{1}-\mathrm{C}_{4}$ hydrocarbons, $\mathrm{H}_{2}, \mathrm{CO}_{2}$ and $\mathrm{CO}[27,52]$ ) was calculated by subtracting liquid product mass from feed mass. The mass of unidentified components was then calculated by subtracting the identified liquid products and uncondensed gases from feed mass. From Table S4, it can be seen that at $\tau=1 \mathrm{~s}$, nearly all liquid products were identified. However, for experiments at higher $\tau$ identification of all products was difficult, due to the vast number of small peaks that were present on the GC-FID chromatogram.

Between 10-25\% of the products remained unidentified in the recovered liquid with higher $\tau$. Other studies have also reported similar mass closure of identifiable products (typically $30-80 \%)[5,27,32]$. At higher $\tau$, secondary reactions are enhanced and the concentrations of LtHCs increased. These Lt-HCs consisted of several components. For instance, the detailed results of hydrocarbons identification (as described in Section 3.5) showed 360 distinct peaks on the GC-FID chromatogram. Although each unidentified compound was likely produced at a low 
concentration, the cumulative effect is significant. A majority of the unidentified products were in the range of Lt-HCs (GC column elution temperature $<90^{\circ} \mathrm{C}$ ).

To assess the products at an extreme reaction condition, soybean oil was pyrolyzed at 550 ${ }^{\circ} \mathrm{C}$ and $\tau=300$ s. Under this severe reaction condition, liquid products likely underwent extensive cracking to small molecules which resulted in a high (50\%) production of uncondensed gases (Table S4, Supplementary Information). The high content of Lt-HCs (23.1\% of feed) under these conditions is likely due to break down of unsaturated Hy-HCs, decarboxylation of S-FAs, and degradation of L-FAs. As a result, low mass of fatty acids (long- and short-chain) as well as HyHCs was observed.

\subsection{Product distillation and detailed hydrocarbon analysis}

Products of soybean oil pyrolysis at $\mathrm{T}_{\mathrm{rxn}}=500{ }^{\circ} \mathrm{C}$ and $\tau=60 \mathrm{~s}$ were distilled to separate free fatty acids from hydrocarbons, since a high yield of non-glyceride liquid products ( $85 \%$; Figure 2c) was achieved at these experimental conditions. Distillation was performed under vacuum (60 $\mathrm{mm} \mathrm{Hg}$ ) to minimize thermal degradation (if any) of liquids during the separation. The goal of distillation was to separate L-FAs from other components. To estimate the appropriate distillation temperature, boiling point (b.p.) of hydrocarbons and fatty acids were estimated at the vacuum conditions employed. The b.p. of heptadecane (highest carbon-number hydrocarbon in our liquid products) at $60 \mathrm{~mm} \mathrm{Hg}$ was estimate to be $200{ }^{\circ} \mathrm{C}$ from extrapolation of its normal b.p. using the correlation provided by Maxwell and Bonnell [53]. For fatty acids, the b.p. values at $10 \mathrm{~mm} \mathrm{Hg}$ from Cermak et al. [54] were extrapolated to a pressure of $60 \mathrm{~mm}$ $\mathrm{Hg}$ [53]. From these correlations, the b.p. of oleic and palmitic acid were estimated to be 271 and $261{ }^{\circ} \mathrm{C}$, respectively. Since there was sufficient difference in b.p.s of hydrocarbons and L-FAs at $60 \mathrm{~mm} \mathrm{Hg}$, vacuum distillation was performed at $200{ }^{\circ} \mathrm{C}$. 

temperature). After $4.5 \mathrm{~h}$, no further boiling of the liquid phase was visually apparent. Thereafter, the distilled fraction (DF) and the residue fraction (RF) were analyzed using GC-FID. Figure S3 (Supplementary Information) shows the GC-FID chromatogram of the DF. Identification of compounds was performed by matching retention time of analytes with standard mixtures (listed in the materials section) and was confirmed by GC-MS through a comparison of MS spectra of analytes with corresponding entries from the NIST 2008 database. The GC-FID analysis detected 360 peaks with relative concentration above $0.01 \%$ in the distilled fraction. Since quantification of all individual compounds using their corresponding standards is difficult, chemicals were quantified using relative peak areas.

Table S5 (Supplementary Information) shows the more abundant compounds (with concentrations approximately above $0.1 \%$ ) that represent nearly $85 \%$ of the DF. As observed, different classes of hydrocarbons were present in the products. Light hydrocarbons in the range of gasoline $\left(\mathrm{C}_{5}-\mathrm{C}_{12}\right)$ comprise almost $65 \%$ of the $\mathrm{DF}$. The major compounds identified are $\mathrm{C}_{5}-\mathrm{C}_{17}$ alkanes and alkenes, aromatics including benzene, toluene, ethylbenzene, propylbenzene, buthylbenzene and xylene, and cyclic compounds such as cyclooctane and cyclopentane methylene. Table 1 shows the relative mass of aromatics, olefins, paraffin and cyclic compounds in the DF. While aromatic compounds improve the octane number of a fuel, their use in gasoline is strictly regulated by EPA air quality standards [8]. Our DF contains $13 \%$ aromatic, which is below the regulated value (maximum 20\%). Formation of aromatics can occur due to DielsAlder reaction and/or intramolecular radical cyclization. In Diels-Alder reaction, a diene and alkene reacts and form polysubstituted cyclohexenes and then via hydrogenation polysubstituted cyclohexanes and via dehydrogenation polysubstituted aromatic produce [55]. It can also be 
noted that majority of olefins and paraffins are unbranched. Dienes (e.g. undecadiene, tridecadiene, and tetradecadiene) were also present in the DF.

Figure S4 (Supplementary Information) shows the GC-FID chromatogram and Table S6 (Supplementary Information) shows the composition of residual fraction (RF) of the distillation. It can be clearly seen that $\mathrm{C}_{18}$ fatty acids were the major (59\%) components of the RF. In addition, much smaller amounts of $\mathrm{C}_{16}$ fatty acids, and $\mathrm{C}_{13}-\mathrm{C}_{17}$ hydrocarbons were also observed in the RF. In contrast with GC-FID results of the DF (Figure S3, supplementary data), the analysis of the RF (Figure S4, Supplementary Information) showed no significant peak prior to a retention time of $100 \mathrm{~min}$. This indicates that the simple distillation (that was used in our experiment) could separate most hydrocarbons from L-FAs. Although the RF contained small amounts of $\mathrm{C}_{13}-\mathrm{C}_{17}$ hydrocarbons ( 11\%), with a better control of distillation conditions, more purified L-FAs could possibly be recovered.

S-FAs in DF and RF were identified and quantified separately since derivatization of SFAs was needed to improve the sensitivity of detection by GC-FID (as described in Section 3.4). The procedure for derivatization was similar to transesterification of soybean oil, which was explained in Section 2.4. Derivatized S-FAs were quantified by comparison with FID response of known methyl ester standards. Figure S5 (Supplementary Information) shows the GC-FID chromatogram of the derivatized DF and RF. The composition of S-FAs in DF and RF is given in Table S7 (Supplementary Information). From these data, S-FAs comprised $\sim 7 \%$ of the DF with heptanoic acid (C7-FAs) as the major S-FAs. Also, S-FAs (mainly C10-FAs) comprised $\sim 9 \%$ of the RF. It is important to mention that the GC-FID analysis of the DF (Figure S5a, Supplementary Information) did not show any peak correspond to L-FAs. This indicates that all L-FAs (of the liquid products at experiment 500-60) remained in RF. 
Our distillation results show that pyrolysis products could be relatively easily separated into hydrocarbon-rich and L-FAs-rich fractions. The hydrocarbon containing fraction could then be converted to fuels or further distilled to recover aromatics.

\subsection{Feasibility of isolating oleic acid from soy oil via pyrolysis}

Analysis of products from vegetable oil pyrolysis suggested that oleic acid was relatively thermally-stable (Table S2, Supplementary Information). To better understand the thermal degradation of the mono-unsaturated oleic acid under more controlled conditions (in the absence of other poly-unsaturated fatty acids), pyrolysis of enriched oleic acid was performed. The experimental set-up was kept similar to pyrolysis of soybean oil in order to compare the results of oleic acid and soybean oil pyrolysis. The feed contained small amounts of saturated fatty acids- C16:0 ( 4\%), C14:0 ( 3\%) and C17:0 ( 2\%); oleic acid was $\sim 85 \%$ of the feed. Pyrolysis was carried out at $450{ }^{\circ} \mathrm{C}$ and $\tau$ of $60 \mathrm{~s}$ and $300 \mathrm{~s}$ (conditions that showed low degradation of oleic acid during soybean oil pyrolysis). Identification of feed and pyrolysis products was performed using GC-MS, and quantification of components was carried out via GC-FID. Figure S6 shows the GC-MS chromatogram of feed (Figure S6a, Supplementary Information), and pyrolysis products at $450{ }^{\circ} \mathrm{C}$ and $\tau$ of $60 \mathrm{~s}$ (Figure S6b, Supplementary Information) and $300 \mathrm{~s}$ (Figure S6c, Supplementary Information). Product composition at $450{ }^{\circ} \mathrm{C}$ and $\tau=60 \mathrm{~s}$ is nearly same as the feed (Table S8, Supplementary Information), which indicates that the extent of degradation was small under these conditions. The heptadecene (2.9\%) was likely produced due to decarboxylation of oleic acid. Even at $\tau=300 \mathrm{~s}$, a large portion of the pyrolysis products was still oleic acid ( $\sim 63 \%$ ), and only $\sim 4.3 \%$ decanoic acid (due to C-C cleavage) was observed in addition to heptadecene (5.7\%). 
Overall, pyrolysis results of oleic acid demonstrate that oleic acid is thermally stable and can be largely recovered in its native fatty acid form after pyrolysis. In contrast, poly-unsaturated fatty acids are much more thermally labile and undergo extensive degradation, as evidenced by the low concentration of these in the products of soybean oil pyrolysis (Table S2, Supplementary Information). From Table S8 and Figure S6 (Supplementary Information), approximately 25\% of oleic acid degraded into smaller molecules at $450{ }^{\circ} \mathrm{C}$ and $\tau$ of $300 \mathrm{~s}$. However, when soybean oil was pyrolyzed under similar conditions, a slightly greater amount $(\sim 33 \%)$ of oleic acid (from triglyceride) was measured to be degraded (Table S2, Supplementary Information). The higher degradation of oleic acid in the triglyceride feed could be attributed to more free radical formation due to extensive degradation of the thermally labile linoleic/linolenic acid, which may have contributed to more extensive cracking of oleic acid. Moreover, in pyrolysis of triglycerides, the produced long chain fatty acids (as a result of glycerol backbone release) are in the form of free radicals ( $\mathrm{RCOO})^{\circ}$ ) and perhaps these highly reactive fatty acid radicals are more prone to crack than oleic acid in a whole free fatty acid form. Oleic acid is an important precursor in oleochemicals $[28,56,57]$ and our results suggest that pyrolysis could be used for high yield recovery of this fatty acid from oleic acid-rich feedstocks such as sunflower oil.

\section{Conclusions}

In this study, pyrolysis of soybean oil was performed to convert it into fuels and chemicals. An atomizer was used to introduce the oil into the reactor in the form of micron-sized droplets to rapidly volatilize oil and achieve short vapor residence time. As a result, neartheoretical yields of liquid products (up to $88 \%$ relative to feed mass) were achieved. The liquid products were comprised of light- $\left(\mathrm{C}_{5}-\mathrm{C}_{12}\right)$ and heavy- $\left(>\mathrm{C}_{12}\right)$ hydrocarbons in addition to short- 
$\left(\mathrm{C}_{6}-\mathrm{C}_{12}\right)$ and long- $\left(\mathrm{C}_{16}-\mathrm{C}_{18}\right)$ chain fatty acids. Distillation of liquid products resulted in distinct hydrocarbon-rich and long-chain fatty acids-rich fractions. The hydrocarbon-rich fraction contained paraffin $(23 \%)$, olefin $(32 \%)$, aromatic $(13 \%)$, cyclic compounds $(9 \%)$ and dienes $(5 \%)$.

In contrast with transesterification that produces biodiesel but does not produce drop-in hydrocarbon fuels, pyrolysis can generate multiple fuels/fuel precursors (e.g. gasoline, jet fuel and diesel) and chemicals (e.g. olefin and aromatics as primary petrochemicals; fatty acids for oleochemicals). In addition, low quality oils with high free fatty acid content are also suitable as pyrolysis feedstocks, but would not be usable for biodiesel production. Thus far, low yield of liquid products has remained the major obstacle for commercialization of vegetable oil pyrolysis since feedstock price is the dominant cost for fuel production from triglycerides. In this study, we have demonstrated that our simple reactor design allows for near-quantitative yield of products. Further, since the design is based on the widely used industrial practice of atomization, the reactor system is easily scalable for commercial use and would allow the implementation of pyrolysis as a viable alternative to transesterification for production of fuels and chemicals from vegetable oils.

\section{Acknowledgments}

This project was supported by (1) the National Science Foundation through the Sustainable Energy Pathways Program (award\# CHE-1230609) and (2) the US Department of Energy Bioenergy Technologies Office (award\# DE-EE0005993).

\section{References}


[1] Demirbas A. Political, economic and environmental impacts of biofuels: A review. Applied Energy. 2009;86, Supplement 1:S108-S17.

[2] Labecki L, Cairns A, Xia J, Megaritis A, Zhao H, Ganippa LC. Combustion and emission of rapeseed oil blends in diesel engine. Applied Energy. 2012;95:139-46.

[3] Buzetzki E, Sidorová K, Cvengrošová Z, Cvengroš J. Effects of oil type on products obtained by cracking of oils and fats. Fuel Processing Technology. 2011;92:2041-7.

[4] Yan S, DiMaggio C, Wang H, Mohan S, Kim M, Yang L, et al. Catalytic Conversion of Triglycerides to Liquid Biofuels Through Transesterification, Cracking, and Hydrotreatment Processes. Current Catalysis. 2012;1:41-51.

[5] Wiggers VR, Zonta GR, Franca AP, Scharf DR, Simionatto EL, Ender L, et al. Challenges associated with choosing operational conditions for triglyceride thermal cracking aiming to improve biofuel quality. Fuel. 2013;107:601-8.

[6] Zandonai CH, Yassue-Cordeiro PH, Castellã-Pergher SB, Scaliante MHNO, FernandesMachado NRC. Production of petroleum-like synthetic fuel by hydrocracking of crude soybean oil over ZSM5 zeolite-Improvement of catalyst lifetime by ion exchange. Fuel. 2016;172:22837.

[7] Chiaramonti D, Rizzo AM, Spadi A, Prussi M, Riccio G, Martelli F. Exhaust emissions from liquid fuel micro gas turbine fed with diesel oil, biodiesel and vegetable oil. Applied Energy. 2013;101:349-56.

[8] Lestari S, Mäki-Arvela P, Beltramini J, Lu GQM, Murzin DY. Transforming Triglycerides and Fatty Acids into Biofuels. ChemSusChem. 2009;2:1109-19.

[9] Maher KD, Bressler DC. Pyrolysis of triglyceride materials for the production of renewable fuels and chemicals. Bioresource Technology. 2007;98:2351-68.

[10] Demirbas A. Biodiesel production from vegetable oils via catalytic and non-catalytic supercritical methanol transesterification methods. Progress in Energy and Combustion Science. 2005;31:466-87.

[11] Schwab AW, Bagby MO, Freedman B. Preparation and properties of diesel fuels from vegetable oils. Fuel. 1987;66:1372-8.

[12] Williamson A-M, Badr O. Assessing the viability of using rape methyl ester (RME) as an alternative to mineral diesel fuel for powering road vehicles in the UK. Applied Energy. 1998;59:187-214.

[13] Gautam R, Kumar N, Pali HS, Kumar P. Experimental studies on the use of methyl and ethyl esters as an extender in a small capacity diesel engine. Biofuels. 2016:1-10.

[14] Schuchardt U, Sercheli R, Vargas RM. Transesterification of vegetable oils: a review. Journal of the Brazilian Chemical Society. 1998;9:199-210.

[15] Glisic SB, Pajnik JM, Orlović AM. Process and techno-economic analysis of green diesel production from waste vegetable oil and the comparison with ester type biodiesel production. Applied Energy. 2016;170:176-85.

[16] Lotero E, Liu Y, Lopez DE, Suwannakarn K, Bruce DA, Goodwin JG. Synthesis of Biodiesel via Acid Catalysis. Industrial \& Engineering Chemistry Research. 2005;44:5353-63.

[17] Demirbaş A. Biodiesel fuels from vegetable oils via catalytic and non-catalytic supercritical alcohol transesterifications and other methods: a survey. Energy Conversion and Management. 2003;44:2093-109.

[18] Wang R, Song B, Zhou W, Zhang Y, Hu D, Bhadury PS, et al. A facile and feasible method to evaluate and control the quality of Jatropha curcus L. seed oil for biodiesel feedstock: Gas chromatographic fingerprint. Applied Energy. 2011;88:2064-70. 

improvement. Bioresource Technology. 1996;56:13-8.

[20] Lima DG, Soares VCD, Ribeiro EB, Carvalho DA, Cardoso ÉCV, Rassi FC, et al. Diesellike fuel obtained by pyrolysis of vegetable oils. Journal of Analytical and Applied Pyrolysis. 2004;71:987-96.

[21] Patil PD, Deng S. Optimization of biodiesel production from edible and non-edible vegetable oils. Fuel. 2009;88:1302-6.

[22] Pinto F, Martins S, Gonçalves M, Costa P, Gulyurtlu I, Alves A, et al. Hydrogenation of rapeseed oil for production of liquid bio-chemicals. Applied Energy. 2013;102:272-82.

[23] Schwab AW, Dykstra GJ, Selke E, Sorenson SC, Pryde EH. Diesel fuel from thermal decomposition of soybean oil. J Am Oil Chem Soc. 1988;65:1781-6.

[24] Alencar JW, Alves PB, Craveiro AA. Pyrolysis of tropical vegetable oils. Journal of Agricultural and Food Chemistry. 1983;31:1268-70.

[25] Fortes ICP, Baugh PJ. Study of analytical on-line pyrolysis of oils from Macauba fruit (Acrocomia sclerocarpa M) via GC/MS. Journal of the Brazilian Chemical Society. 1999;10:469-77.

[26] Fortes ICP, Baugh PJ. Study of calcium soap pyrolysates derived from Macauba fruit (Acrocomia sclerocarpa M.). Derivatization and analysis by GC/MS and CI-MS. Journal of Analytical and Applied Pyrolysis. 1994;29:153-67.

[27] Idem RO, Katikaneni SPR, Bakhshi NN. Thermal Cracking of Canola Oil: Reaction Products in the Presence and Absence of Steam. Energy \& Fuels. 1996;10:1150-62.

[28] Ameh Abel G, Oliver Nguyen K, Viamajala S, Varanasi S, Yamamoto K. Cross-metathesis approach to produce precursors of nylon 12 and nylon 13 from microalgae. RSC Advances. 2014;4:55622-8.

[29] Behr A, Westfechtel A, Pérez Gomes J. Catalytic processes for the technical use of natural fats and oils. Chemical engineering \& technology. 2008;31:700-14.

[30] Almeida HD, Correa OA, Eid JG, Ribeiro HJ, de Castro DR, Pereira MS, et al. Production of biofuels by thermal catalytic cracking of scum from grease traps in pilot scale. Journal of Analytical and Applied Pyrolysis. 2016;118:20-33.

[31] Chang C-C, Wan S-W. China's Motor Fuels from Tung Oil. Industrial \& Engineering Chemistry. 1947;39:1543-8.

[32] Kubatova A, Luo Y, Stavova J, Sadrameli SM, Aulich T, Kozliak E, et al. New path in the thermal cracking of triacylglycerols (canola and soybean oil). Fuel. 2011;90:2598-608.

[33] Bridgwater A, Peacocke G. Fast pyrolysis processes for biomass. Renewable and Sustainable Energy Reviews. 2000;4:1-73.

[34] Trubetskaya A, Jensen PA, Jensen AD, Llamas ADG, Umeki K, Gardini D, et al. Effects of several types of biomass fuels on the yield, nanostructure and reactivity of soot from fast pyrolysis at high temperatures. Applied Energy. 2016;171:468-82.

[35] Zhang XS, Lei HW, Zhu L, Qian M, Zhu XL, Wu J, et al. Enhancement of jet fuel range alkanes from co-feeding of lignocellulosic biomass with plastics via tandem catalytic conversions. Applied Energy. 2016;173:418-30.

[36] Wiggers VR, Wisniewski Jr A, Madureira LAS, Barros AAC, Meier HF. Biofuels from waste fish oil pyrolysis: Continuous production in a pilot plant. Fuel. 2009;88:2135-41.

[37] Wisniewski Jr A, Wiggers VR, Simionatto EL, Meier HF, Barros AAC, Madureira LAS. Biofuels from waste fish oil pyrolysis: Chemical composition. Fuel. 2010;89:563-8. 

from continuous fast pyrolysis of soybean oil: A pilot plant study. Bioresource Technology. 2009;100:6570-7.

[39] Luo Y, Ahmed I, Kubátová A, Št'ávová J, Aulich T, Sadrameli SM, et al. The thermal cracking of soybean/canola oils and their methyl esters. Fuel Processing Technology. 2010;91:613-7.

[40] Goodrum JW, Geller DP. Rapid thermogravimetric measurements of boiling points and vapor pressure of saturated medium- and long-chain triglycerides. Bioresource Technology. 2002;84:75-80.

[41] Bollin PM, Viamajala S. Reactive Extraction of Triglycerides as Fatty Acid Methyl Esters using Lewis Acidic Chloroaluminate Ionic Liquids. Energy \& Fuels. 2012;26:6411-8.

[42] Nelson DR, Viamajala S. One-pot synthesis and recovery of fatty acid methyl esters (FAMEs) from microalgae biomass. Catalysis Today. 2016;269:29-39.

[43] Dalmoro A, Barba AA, Amore M. Analysis of Size Correlations for Microdroplets Produced by Ultrasonic Atomization. The Scientific World Journal. 2013;2013:7.

[44] Omer K, Ashgriz N. Spray Nozzles. In: Ashgriz N, editor. Handbook of Atomization and Sprays: Springer US; 2011. p. 497-579.

[45] Rajan R, Pandit AB. Correlations to predict droplet size in ultrasonic atomisation. Ultrasonics. 2001;39:235-55.

[46] Noureddini H, Teoh BC, Davis Clements L. Densities of vegetable oils and fatty acids. Journal of the American Oil Chemists Society. 1992;69:1184-8.

[47] Esteban B, Riba J-R, Baquero G, Puig R, Rius A. Characterization of the surface tension of vegetable oils to be used as fuel in diesel engines. Fuel. 2012;102:231-8.

[48] Fasina OO, Colley Z. Viscosity and Specific Heat of Vegetable Oils as a Function of Temperature: $35^{\circ} \mathrm{C}$ to $180^{\circ} \mathrm{C}$. International Journal of Food Properties. 2008;11:738-46.

[49] Maddi B, Viamajala S, Varanasi S. Comparative study of pyrolysis of algal biomass from natural lake blooms with lignocellulosic biomass. Bioresource Technology. 2011;102:11018-26. [50] Zhenyi C, Xing J, Shuyuan L, Li L. Thermodynamics calculation of the pyrolysis of vegetable oils. Energy Sources. 2004;26:849-56.

[51] Castro C, Rust F. Thermal decomposition of acrolein. The attack of methyl and t-butoxy free radicals on acrolein. Journal of the American Chemical Society. 1961;83:4928-32.

[52] Meier HF, Wiggers VR, Zonta GR, Scharf DR, Simionatto EL, Ender L. A kinetic model for thermal cracking of waste cooking oil based on chemical lumps. Fuel. 2015;144:50-9.

[53] Maxwell JB, Bonnell LS. Derivation and Precision of a New Vapor Pressure Correlation for Petroleum Hydrocarbons. Industrial \& Engineering Chemistry. 1957;49:1187-96.

[54] Steven C. Cermak RLEaJAK. Distillation of Natural Fatty Acids and Their Chemical Derivatives. In: Zereshki S, editor. Distillation - Advances from Modeling to Applications: InTech; 2012.

[55] Kubátová A, Št’ávová J, Seames WS, Luo Y, Sadrameli SM, Linnen MJ, et al. Triacylglyceride thermal cracking: pathways to cyclic hydrocarbons. Energy \& Fuels. 2011;26:672-85.

[56] Biermann U, Bornscheuer U, Meier MAR, Metzger JO, Schafer HJ. Oils and Fats as Renewable Raw Materials in Chemistry. Angew Chem-Int Edit. 2011;50:3854-71.

[57] Moser BR, Sharma BK, Doll KM, Erhan SZ. Diesters from oleic acid: Synthesis, low temperature properties, and oxidation stability. J Am Oil Chem Soc. 2007;84:675-80. 


\section{Graphical abstract}






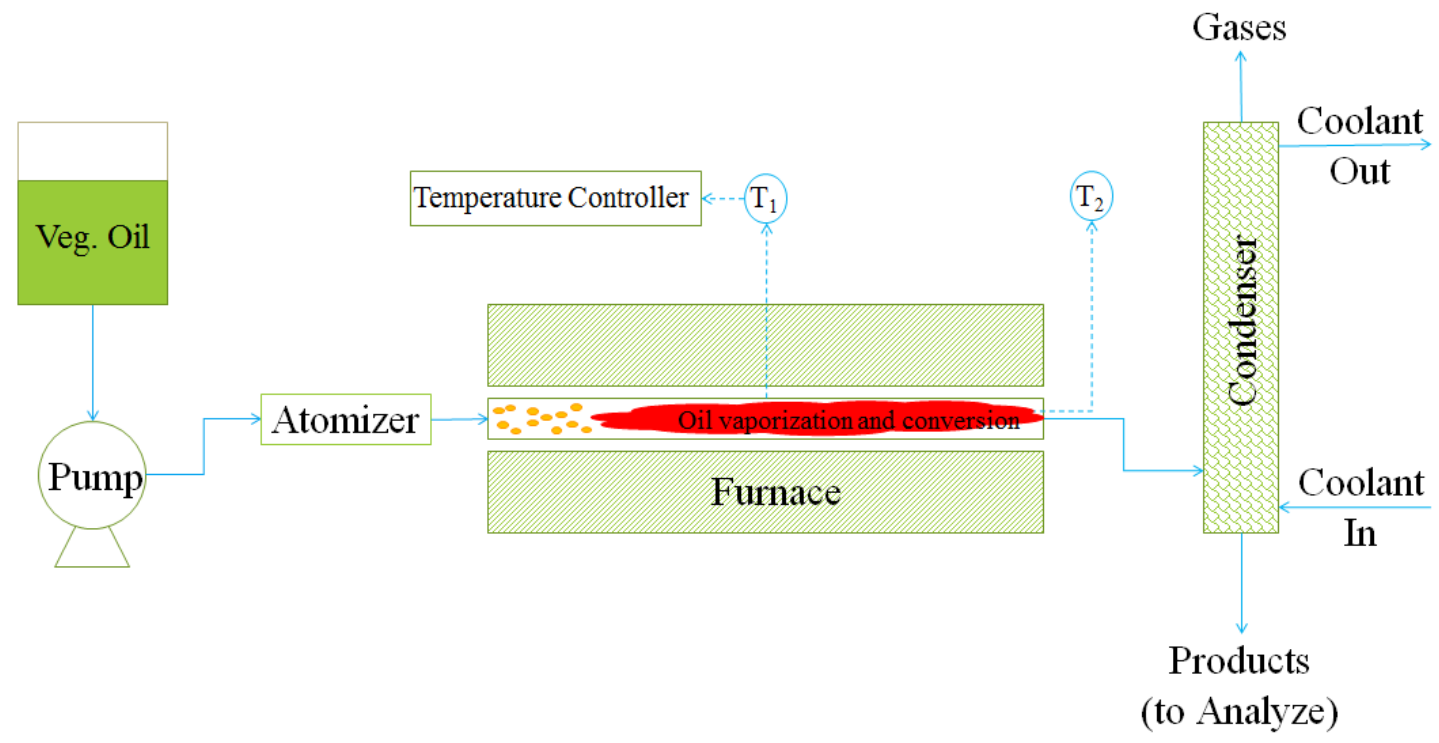

Figure 1. Schematic diagram of pyrolysis system. 


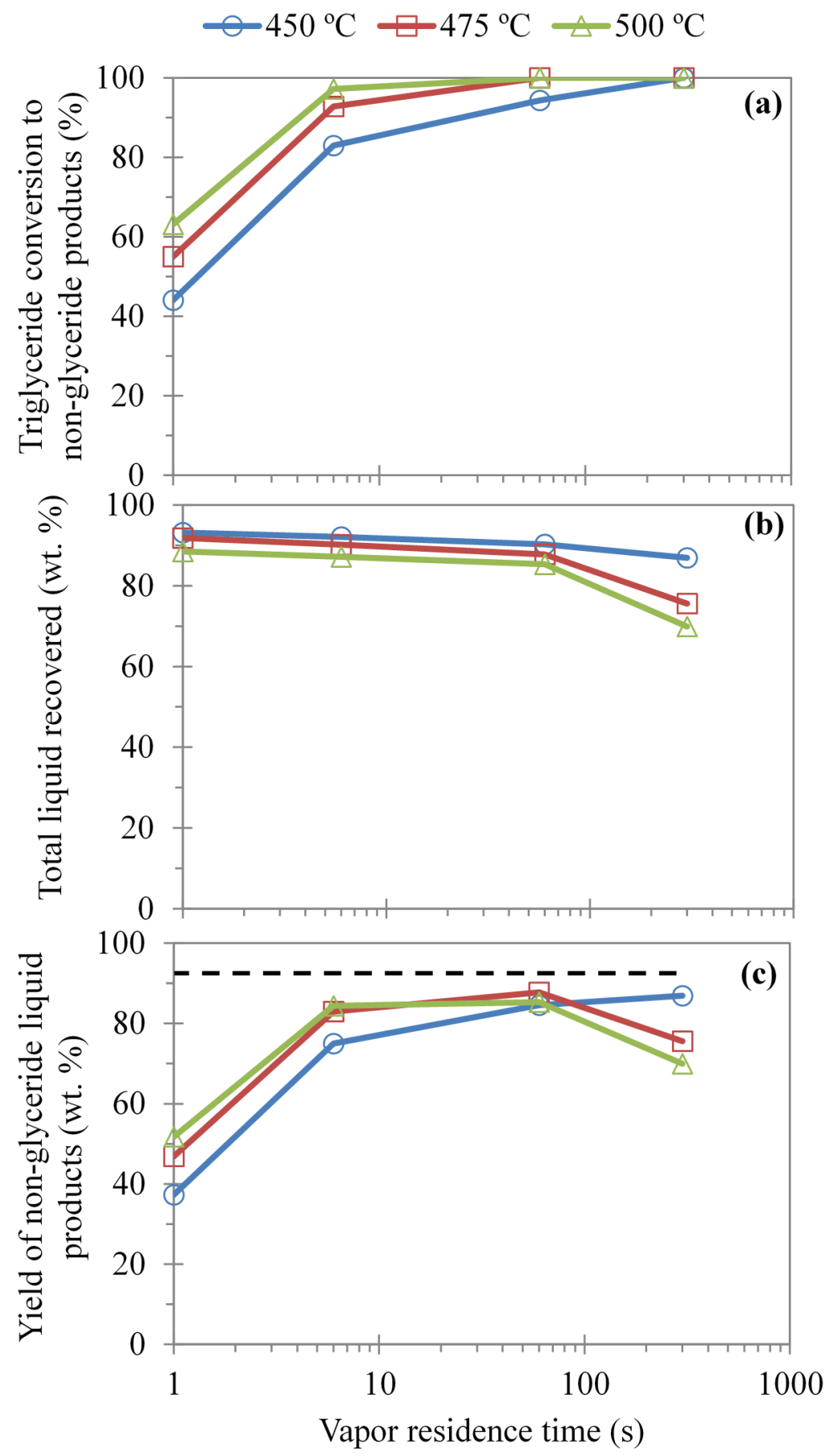

Figure 2. (a) Conversion of feed to non-glyceride products (see Equation 1), (b) yield of liquid recovered (see Equation 2), and (c) yield of non-glyceride liquid products (see Equation 3) versus vapor residence time at the pyrolysis temperatures. Dashed line represents the theoretical yield of non-glyceride liquid products. 


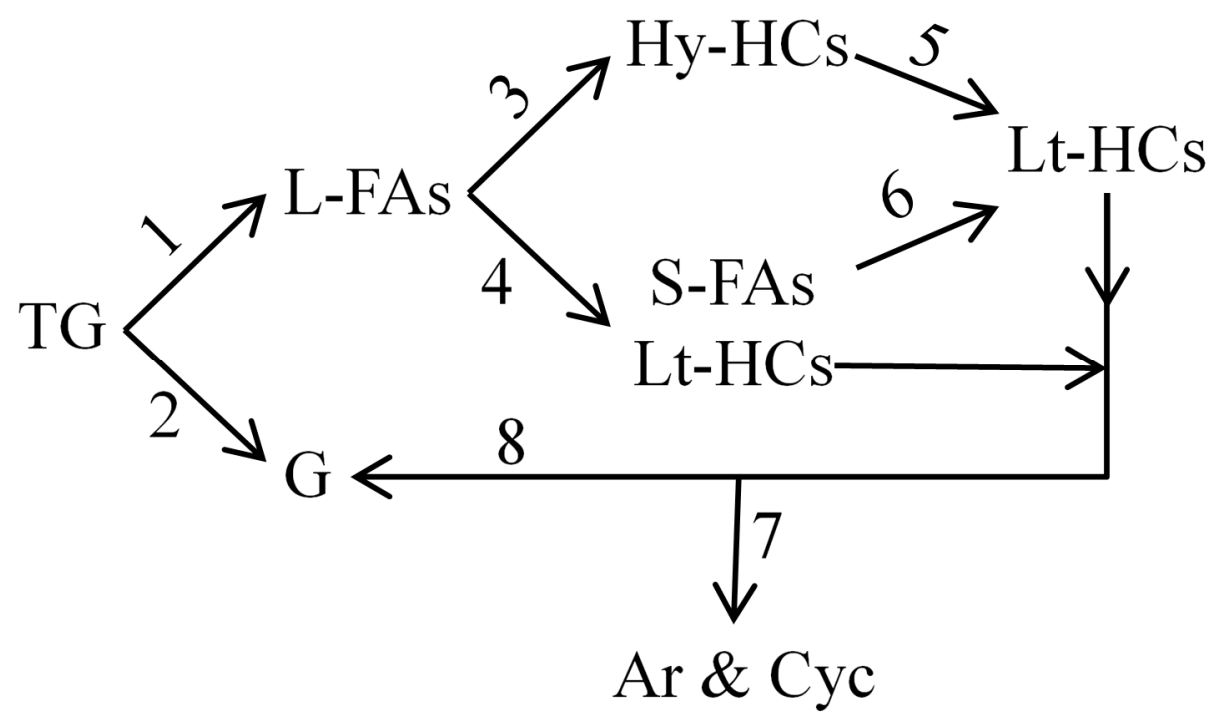

Figure 3. A general thermal cracking mechanism of soybean oil: (1) initial cracking of triglyceride that generates free radical RCOO ${ }^{\circ}$ or/and $\mathrm{RCO}^{\circ}(2)$ gases produced as the result of loss of the glycerol backbone (3) decarboxylation and/or decarbonylation of long chain fatty acids, followed by hydrogenation and/or dehydrogenation that produces heavy hydrocarbons (4) C-C double bond cleavage of long chain fatty acids to produce short chain fatty acids and light hydrocarbons (5) long chain hydrocarbons breakdown due to cleavage of unsaturated C-C bonds to produce light hydrocarbons (6) decarboxylation of short chain fatty acids to produce light hydrocarbons (7) Diels-Alder reaction (reaction between a diene and alkene) to produce cyclic compounds and/or aromatics (due to dehydrogenation of cyclic compounds) (8) breakdown of light hydrocarbons to noncondensable gases (e.g. ethylene elimination). TG: triglyceride, L-FAs: long-chain fatty acids, G: gases, Hy-HC: heavy hydrocarbons, S-FAs: short-chain fatty acids, Lt-HC: light hydrocarbons, Ar: aromatic, and Cyc: cyclic compounds. 

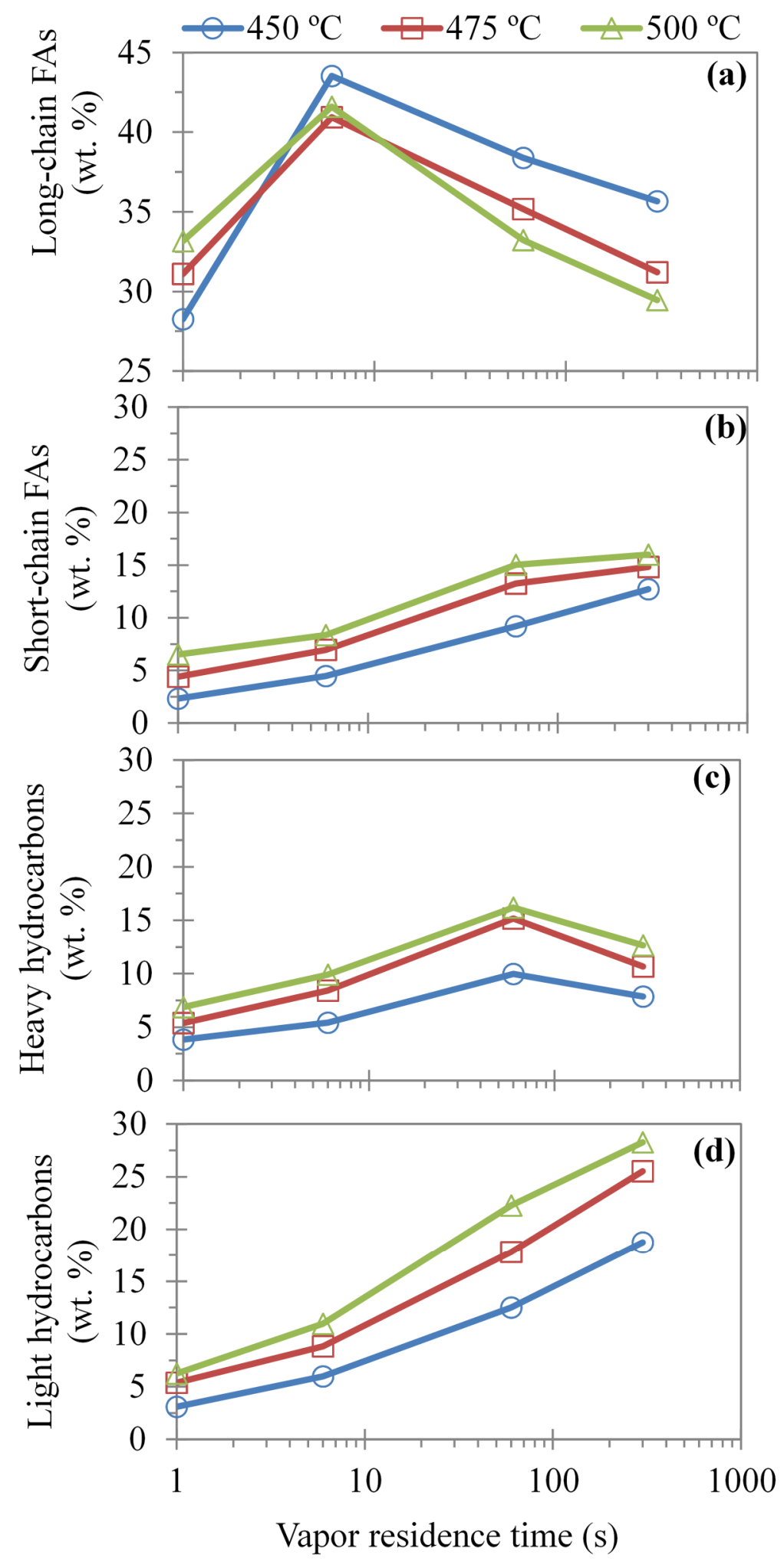

Figure 4. Content of long-chain fatty acids (a), short-chain fatty acids (b), heavy hydrocarbons (c), and light hydrocarbons (d) in the recovered pyrolysis liquids at the tested reaction conditions. 